\title{
材料科学への数学的アプローチ 一一自己相似性について—
}

1. は じめ に

近年, ソリトンやカオスなどの新しい数学的概念が諸科学 に導入されて，それぞれ意義有る成果を生んでいる模様であ る、ここでは，新たに再発見された，ワイヤストラウス以来 の概念であるところの「自己相似性」をとりあげて，その数 学的背景を確認したい。全体の構造が，その部分の構造と相 似であるような, いわゆる, 自己相似構造はデンドライトの 形成，固体表面層の形成などの議論に見られるように，材料 科学に打いても，極めて重要な概念のひとつとなりつつあ る、実際，その物質科学への応用関するものだけでも，そ の研究成果は膨大な数にのぽっている。しかしフラクタルの 名を通して普及して来たこの概念も，ややもするとその定義 そのものが不明瞭なまま利用されていることも，また，その 適用範囲に対する数学的に十分な反省がないまま利用されて いることも少なくないよらである。そこで，ここでは「自己 相似性 (self-similarity)」の数学上の定義を確認し, この構 造が得られるためのひとつの十分条件を提示したい.なお, ここでは通常用いられている縮小写像の定義を新たにより一 般化して提示するので, 補助定理, 中心的命題ともに，完全 な証明をつけることとした。なお，自己相似性の数学に関す る文献としては，八ッチンソン(1)が基本的であろら。初等的 な教科書としては，文献の $(2)$ が適当と思われる。多くの具 体的な戝が掲載されており，視覚的理解の助けとなるものと 思われる。な抏，内容をでさるだけ self-containedなものと するために，本文の後に注を付して，数学上の用語の若干の 説明を行った。

\section{2. 自己相似性の定義とその存在のための十分条件}

$(X, d)$ を集合 $X$ 亿距離 $d$ を定めて得られるところの距離 空間とする。以下の性質 (1)をもつところの, 距離空間 $(X, d)$ からそれ自身への写像 $f:(X, d) \rightarrow(X, d)$ を縮小写像 とよぶ.

$$
d(f(x), f(y)) \leqq \alpha(t) d(x, y), \quad d(x, y)<t
$$

ここで, $\alpha(t), t>0$ は, $0 \leqq \alpha(t)<1$ なる実数值関数である.

$\alpha(t) \equiv C, 0 \leqq C<1$ と和いた場合が最も一般的な縮小写像 である。

縮小写像に関して以下の補助定理が成り立つ.

[補助定理］完備距離空間 $(X, d)$ 注1)上で, 評価 $(1)$ を又 たす写像 $f$ はただひとつの不動点をもつ、すなわち， $f(\bar{x})$ $=\bar{x}$ となる点 $\bar{x} か ゙(X, d)$ 内にただひとつ存在する.

（証明）点 $x_{0}$ 老 $(X, d)$ 内に任意に定める. $f\left(x_{n}\right)=x_{n+1}$, $n=0,1,2, \cdots$ にたがって $(X, d)$ 内に点列 $\left\{x_{n}\right\}$ を作る．任意 の $n \geqq 2$ に対して,

$$
\begin{aligned}
d\left(x_{n}, x_{n+1}\right) & =d\left(f\left(x_{n-1}\right), f\left(x_{n}\right)\right) \leqq \alpha_{n-1, n} d\left(x_{n-1}, x_{n}\right) \\
& =\alpha_{n-1, n} d\left(f\left(x_{n-2}\right), f\left(x_{n-1}\right)\right) \\
& \leqq \alpha_{n-1, n} \alpha_{n-2, n-1} d\left(x_{n-2}, x_{n-1}\right) \\
& =\cdots \leqq \alpha_{n-1, n} \cdots \alpha_{0,1} d\left(x_{0}, x_{1}\right)<d\left(x_{0}, x_{1}\right)
\end{aligned}
$$

(ここで $\alpha_{i-1, i}$ は $\alpha\left(t_{i}\right)$ の略記であって, $t_{i}$ は $d\left(x_{i-1}, x_{i}\right)<t_{i}$ なる任意の正数である.)となるから，

$$
d\left(f\left(x_{n}\right), f\left(x_{n+1}\right)\right) \leqq \alpha\left(d\left(x_{0}, x_{1}\right)\right) d\left(x_{n}, x_{n+1}\right)
$$

を得る。ここで $\alpha\left(d\left(x_{0}, x_{1}\right)\right)=\beta$ とおけげ

$$
\begin{aligned}
& d\left(x_{n}, x_{n+1}\right) \leqq \beta d\left(x_{n-1}, x_{n}\right) \\
& d\left(x_{n-1}, x_{n}\right) \leqq \beta d\left(x_{n-2}, x_{n-1}\right)
\end{aligned}
$$

に注意すれば，

* 早稲田大学助教授; 理工学部材料工学科 ( 169 東京都新宿区大久保3-4-1 59号館324)

A Mathematical Approach to the Materials Science - On a Self-Similarity -; Akihiko Kitada (School of Science and Engineering, Waseda University, Tokyo)

Keywords: self-similarity, set dynamical system, nonlinear analysis, dendrite, polycrystalline matter, crystal lattice 1993年 8 月23日受理 


$$
d\left(x_{n}, x_{n+1}\right) \leqq \beta^{n} d\left(x_{0}, x_{1}\right)
$$

を得るから, 点列 $\left\{x_{n}\right\}$ はコーシー列注1) となる。( $(X, d)$ は完 備であったから，このコーシー列はある点文に収束する。 $f(x)$ は連続関数だから

$$
\lim _{n \rightarrow \infty} f\left(x_{n}\right)=f\left(\lim _{n \rightarrow \infty} x_{n}\right)=f(\bar{x})
$$

であるが, $f\left(x_{n}\right)=x_{n+1}$ であったから,

$$
\lim _{n \rightarrow \infty} f\left(x_{n}\right)=\bar{x}
$$

となって, $f(\bar{x})=\bar{x}$ を得る.

次に不動点の一意性について検討する。いま， $\bar{x}, \bar{x}^{\prime}$ をれ ぞれ写像 $f$ の不動点とする. この 2 点間の距離に関して,

$$
d\left(\bar{x}, \bar{x}^{\prime}\right)=d\left(f(\bar{x}), f\left(\bar{x}^{\prime}\right)\right) \leqq \alpha(t) d\left(\bar{x}, \bar{x}^{\prime}\right), \quad d\left(\bar{x}, \bar{x}^{\prime}\right)<t
$$

となるが，この関係が成り立つためには， $d\left(\bar{x}, \bar{x}^{\prime}\right)=0$ でな 吼ばならない。すなわち, $\bar{x}=\bar{x}^{\prime}$ よなる。

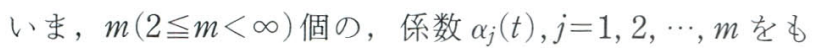
つ, 縮小写像 $f_{1}, f_{2}, \cdots, f_{m}$ が存在して, $X$ の部分集合 $S$ に関 して

$$
\bigcup_{j=1}^{m} f_{j}(S)=S
$$

が成り立つとき, 部分集合 $S$ は自己相似性をもつといら. 与光られた $f_{j}, j=1,2, \cdots, m$ に対する方程式 $(2)$ を解くため に, 以下のような集合力学系 $T$ を考光る.

$$
\begin{aligned}
T:\left(C(X), d_{\mathrm{H}}\right) & \longrightarrow\left(C(X), d_{\mathrm{H}}\right) \\
\stackrel{\Psi}{A} & \longmapsto
\end{aligned}
$$

ここで $C(X)$ は, 距離空間 $(X, d)$ 内の空でないコンパクト 集合全部の集屯りであり， $d_{\mathrm{H}}$ はいわゆるハウスドルフ距 離(3)である.すなわち, $A, B \in C(X)$ に詨して,

$$
d_{\mathrm{H}}(A, B)=\max \left\{\inf \left(\eta>0, N_{\eta}(A) \supset B\right),\right.
$$

$$
\left.\inf \left(\eta>0, N_{\eta}(B) \supset A\right)\right\}^{\text {注 } 2)}
$$

で定義される．ただし

$$
N_{\eta}(A)=\{x \in(X, d) ; \exists a \in A \text { s.t. } d(x, a)<\eta\}
$$

である。ここで, 縮小写像の種類 $m$ が有限であることは

$$
T(A)=\bigcup_{j=1}^{m} f_{j}(A) \in C(X)
$$

となるために厳格である。 $\left(C(X), d_{\mathrm{H}}\right)$ は, $(X, d)$ が完備距 離空間のとき，杂自身完備となることが知られている(4).

したがって, 集合力学系 $T$ がもしふたたび (1)の意味での 縮小写像となることが示せれば，補助定理からただひとつの 不動点 $S$ が $C(X)$ 内に存在することがわかる。すなわち, もとの空間 $(X, d)$ が完備であることが, (2)の意味での自 己相似性をもつコンパクト集合が存在するための十分条件で ある、そこで，Tが（1）の意味での縮小写像になることを 以下の命題で示そう.

[命題] $f_{j}:(X, d) \longrightarrow(X, d), j=1,2, \cdots, m(2 \leqq m<\infty)$ を縮小写像とする。すなわち，

$$
\begin{gathered}
d\left(f_{j}(x) f_{j}(y)\right) \leqq \alpha_{j}(t) d(x, y), \quad d(x, y)<t, \\
0 \leqq \alpha_{j}(t)<1 .
\end{gathered}
$$

このとき，空でないコンパクト集合 $A, B \subset X$ に対して， $d_{\mathrm{H}}(T(A), T(B)) \leqq \alpha(t) d_{\mathrm{H}}(A, B), \quad d_{\mathrm{H}}(A, B)<t$. が成り立つ。ただし，

$$
T(A)=\bigcup_{j=1}^{m} f_{j}(A), \alpha(t)=\max _{j}\left\{\alpha_{j}(t)\right\} .
$$

である。

[証明] $\alpha(t)$ が $0 \leqq \alpha(t)<1$ を満足することは明らかであ る. $d_{\mathrm{H}}(A, B)=\mu<t$ と护悟，その定義から， $\varepsilon を \varepsilon<t-\mu$ なる任意の正数として

$$
B \subset N_{\mu+\varepsilon}(A) .
$$

すなわち, 任意の点 $p \in B$ に対して, $a_{p} \in A$ が存在して

$$
d\left(p, a_{p}\right)<\mu+\varepsilon<t
$$

となっている。したがって，任意の $j$ に対して，

$$
\begin{aligned}
d\left(f_{j}(p), f_{j}\left(a_{p}\right)\right) & \leqq \alpha_{j}(t) d\left(p, a_{p}\right) \\
& <\alpha_{j}(t)(\mu+\varepsilon) \\
& \leqq \alpha(t)(\mu+\varepsilon) .
\end{aligned}
$$

故に, $f_{j}(p) \in N_{\alpha(t)(\mu+\varepsilon)}\left(f_{j}(A)\right)$ となるから,

を得る。したがって，

$$
f_{j}(B) \subset N_{\alpha(t)(\mu+\varepsilon)}\left(f_{j}(A)\right)
$$

$$
\begin{aligned}
T(B) & =\bigcup_{j=1}^{m} f_{j}(B) \subset \bigcup_{j=1}^{m} N_{\alpha(t)(\mu+\varepsilon)}\left(f_{j}(A)\right) \\
& =N_{\alpha(t)(\mu+\varepsilon)}\left(\bigcup_{j=1}^{m} f_{j}(A)\right) \\
& =N_{\alpha(t)(\mu+\varepsilon)}(T(A)) .
\end{aligned}
$$

同様にして，

$$
T(A) \subset N_{\alpha(t)(\mu+\varepsilon)}(T(B))
$$

を得ることができるから，結局，

$$
d_{\mathrm{H}}(T(A), T(B)) \leqq \alpha(t)(\mu+\varepsilon) .
$$

ここで, $\varepsilon>0$ は任意であったから，

$$
d_{\mathrm{H}}(T(A), T(B)) \leqq \alpha(t) \mu, \quad \mu<t
$$

を得る。

以上の議論から,「任意に与えられた有限個の縮小写像に 基づく自己相似性をもつコンパクト部分集合が存在するため には, もとの空間が完備であること」が十分であることが理 解された.

\section{3. 応用}

議論の場が完備距離空間となるよらな, 材料科学に特有な 応用例をひとつあげることにする。おず材料科学の，あるい は金属材料学の固有の視点のひとつとして, 構造の有する欠 陥, 転位, 特定元素の偏析あるいはこれらに基づく結晶粒界 の特徵付けなど，材料の不均一性に対する積極的評価が考㝋 られる。材料は元来不均一なものであり, その組織のくわし い娭討と調整こそが新材料開発の基本であるとする考㝋であ る・ア・プリオリにあらゆる意味で完全であるよらな結晶の 存在が期待できない以上，金属組織学に立脚したこの観点は 今後とも重要であるらと思われる。したがって材料科学への 
数学的アプローチも，主としてこの考光にそってなされるこ とになるだろう。そこで，まず不均一性に対する基本的立場 から, 議論の対象として単結晶ではなく多結晶をとりあげる ことになる。材料の構成単位を原子以下にみるのではなく, 結晶粒とみて, 各結晶粒の集まり方の数学的性質を議論する ことが金属材料学の現実に則した数学的検討の第 1 歩であ ると考觉る.そこで, ここでは, 単結晶の集まり方の幾何学 的性質としての自己相似性を検討寸る. 実在の結晶は 3 次 元以下であららが, 近年の準結晶に関する議論等も考慮に入 れて，すべての議論を一般的に $k$ 次元べクトル空間 $V^{k}$ にお いて行らことにする。まず以下の $l$ を「順序付けられた基に よる格子」と名付忛る.

$$
l=\left\{\sum_{i=1}^{k} u_{i} x_{i} ; u_{i} \in Z\right\},
$$

ここで $Z$ は整数全部の集合を表す. $\left\{x_{1}, x_{2}, \cdots, x_{k}\right\}$ は $V^{k} の$ 順序付けられた基である。すなわち, 基を構成する各べクト ルに番号(ラベル)を付けるわけである。この番号付けが異な れば，格子も異なるものと考光る、すなわち $V^{k}$ の中の部分 集合としては同じものであったとしても，格子としては異な るものと考光るのである、いま, $V^{k}$ には内積 $(\cdot, \cdot)$ が定ま っているものとする. ベクトルのノルム\|・Uはこの内積によ って標準的に導入される。いま, 基は, 条件 $\left(\mathrm{C}_{1}\right),\left(\mathrm{C}_{2}\right)$ によ って特徴付けられているものとする.

$$
\begin{aligned}
& \theta_{i j}=\alpha_{i j}, \quad i, j=1,2, \cdots, k \\
& 0<\delta \leqq\left\|x_{i}\right\| \leqq \eta, \quad i=1,2, \cdots, k .
\end{aligned}
$$

ここで $\theta_{i j}$ は基を構成するベクトル $x_{i}$ と $x_{j}$ との間の角であっ $\tau$

$$
\cos \theta_{i j}=\left(x_{i}, x_{j}\right) /\left\|x_{i}\right\|\left\|x_{j}\right\|, \quad\left(0 \leqq \theta_{i j} \leqq \pi\right) .
$$

で定められる。この角 $\theta_{i j}$ が，あらかじめ与えられた角 $\alpha_{i j}$ に等しいことが要求されるわけである。 $\delta, \eta$ はあらかじめ与 兄られた正数であって, 原子間距離のような格子構成要素間 の間隔に拈ける許容範囲を定めるものである。条件 $\left(\mathrm{C}_{1}\right)$, $\left(\mathrm{C}_{2}\right)$ をみたす格子 $l$ の全体 $\{l\}=L$ に以下の $d$ によって距離 を導入する.

$$
d\left(l, l^{\prime}\right)=\max \left\{\left\|x_{1}-x_{1}^{\prime}\right\|,\left\|x_{2}-x_{2}^{\prime}\right\|, \cdots,\left\|x_{k}-x_{k}^{\prime}\right\|\right\} .
$$

い本, $\left\{l^{n}\right\}$ 劣距離空間 $(L, d)$ 内の任意のコーシー列とする. 有限次元ベクトル空間は任意のノルム $\|\cdot\|$ 亿関して完備であ る(5)から, 角 $\alpha_{i j}$ を保ちながら, lnの基 $\left\{x_{1}^{n}, x_{2}^{n}, \cdots, x_{h}^{n}\right\}$ の各 要素 $x_{i}^{n}$ は，それ枈れ $\bar{x}_{i}$ なる゙クトルに収束寸る。この極限 $\left\{\bar{x}_{1}, \bar{x}_{2}, \cdots, \bar{x}_{k}\right\}$ が条件 $\left(\mathrm{C}_{2}\right)$ を満足していることは見やすい. また，角 $\bar{\theta}_{i j}$ に関しても $\left(\mathrm{C}_{1}\right)$ をみたしていることが以下 のよらにして確められる。すなおち, ノルム\|・\|に関して $\lim _{n \rightarrow \infty} x_{i}^{n}=\bar{x}_{i}$ であり, かつ\|x $x_{i}^{n} \|$ はすべて有界であるから, 任意

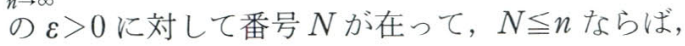

$\left|\cos \bar{\theta}_{i j}-\cos \alpha_{i j}\right|=\left|\left(\bar{x}_{i}, \bar{x}_{j}\right) /\left\|\bar{x}_{i}\right\|\right|\left\|\bar{x}_{j}\right\|-\left(x_{i}^{n}, x_{j}^{n}\right) /\left\|x_{i}^{n}\right\|\left\|x_{j}^{n}\right\| \mid<\varepsilon$ となる、 $\varepsilon>0$ 任意であったから，これは $\bar{\theta}_{i j}=\alpha_{i j}$ を意味す る.したがって $(L, d)$ は完備距離空間となる。 $\alpha_{i j}$ が 1 次独 立なべクトルの間の角である以上，それは一定の条件をみた
していなければならない，以下にその条件を検討する。この 条件としては，次の（*)が成り立つことが十分である.

$\left|\begin{array}{cccc}1 & \cos \alpha_{12} & \cdots & \cos \alpha_{1 k} \\ \cos \alpha_{12} & 1 & \cdots & \cos \alpha_{2 k} \\ \vdots & \vdots & \ddots & \vdots \\ \cos \alpha_{1 k} & \cos \alpha_{2 k} & \cdots & 1\end{array}\right| \neq 0$.

いま, $\sum_{i=1}^{k} \lambda_{i} \bar{x}_{i}=0$ (ゼロベクトル)とする.この式の両辺に $\bar{x}_{i}$ を内積としてか忷れば, 変数 $\lambda_{i}$ に関する連立方程式 $\left\|\bar{x}_{1}\right\| \cos \alpha_{i 1} \lambda_{1}+\cdots+\left\|\bar{x}_{i}\right\| \lambda_{i}+\cdots+\left\|\bar{x}_{k}\right\| \cos \alpha_{i k} \lambda_{k}=0$, $i=1,2, \cdots, k$. を得る。この連立方程式の係数行列の行列式の值がゼ口でな ければ，この方程式は非自明解を持てない。すなわち， $\lambda_{i}$ $=0, i=1,2, \cdots, k$ を得る. これはべクトルの集合 $\left\{\bar{x}_{1}, \bar{x}_{2}, \cdots\right.$, $\left.\bar{x}_{k}\right\}$ が 1 次独立であることを示している. したがって, 角に 関する条件 $(*)$ が成り立つとき, $(L, d)$ は完備距離空間とな るから，2、に捈ける結果から，この条件のもとで， $(L, d)$ 内に自己相似構造をもつコンパクト部分を常に見い出すこと ができることになる。

\section{4. ま め}

本報では, まず自己相似性の数学的定義を確認し, 次に集 合力学系の不動点定理を用いることによって, この性質をも つ構造が現れるための十分条件を求めた. その結果を用いて, $k$ 次元単結晶の格子がどのよらな条件をみたせばその多結晶 中に自己相似性をもつコンパクト部分を見い出すことができ るかについて検討した。

注 1) $\left\{x_{n}\right\}$ 距離空間 $(X, d)$ に抢ける点列とする. 任意の 正数 $\varepsilon$ に対して,

$$
N \leqq n, m \Longrightarrow d\left(x_{n}, x_{m}\right)<\varepsilon
$$

が成り立つように，自然数 $N$ を決定できるとき， $\left\{x_{n}\right\}$ をコ ーシー列とよぶ. 1 点 $x$ を固定し， $x_{n} \equiv x$ と拈いてできる点 列 $\left\{x_{n}\right\}$ はコーシー列であるから, 任意の距離空間において, コーシー列を考光ることができる。をた，収束点列はすべて コーシー列となる. $(X, d)$ の任意のコーシー列が $(X, d)$ 内で 収束するとき， $(X, d)$ を完備距離空間とよぶ.

注 2 ) $\max \{a, b, \cdots, f\}$ は $a$ から $f$ までの数のらち最大の ものを表す。

$$
\text { 文献 }
$$

(1) J. E. Hutchinson: Indiana Univ. Math. J., 30(1981), 713.

(2) 石村貞夫, 石村園子：フラクタル数学, 東京図書, (1990).

(3) J. Dieudonné: Foundations of modern analysis, Academic Press, (1960).

(4) V. I. Istratescu: Fixed point theory, an introduction, D. Reidel Publishing Company, (1981).

(5) L. Schwartz: Cours d'analyse, Tome 1, Hermann, (1967). 